\title{
Архейская тоналит-трондьемит-гранодиоритовая (ТТГ) ассоциация Карелии: этапы формирования, геохимия, происхождение
}

\author{
Чекулаев В.П., Арестова Н.А., Егорова Ю.С. \\ Институт геологии и геохронологии докембрия РАН, Санкт-Петербург, vpchekulaev@mail.ru
}

\begin{abstract}
Аннотация. Обобщены в краткой форме имеющиеся на сегодняшний день данные по времени формирования и химическому составу архейских ТТГ пород Карельской провинции Фенноскандинавского щита. Определены основные этапы формирования ТТ пород в возрастном диапазоне от 3240 до 2650 млн. лет, т.е. от палеоархея почти до границы архея и палеопротерозоя. Приведены характерные особенности состава пород всех выделенных этапов. На основе геологических и изотопных данных показано отсутствие петрогенетической связи ТТ пород с метабазитами зеленокаменных поясов, а также отсутствие их возможной связи с субдукционными процессами.
\end{abstract}

Ключевые слова: Архей, ТТГ, Карельская провинция, Фенноскандинавский щит.

\section{Archean tonalite-trondhjemite-granodiorite (TTG) association of Karelia: stages of formation, geochemistry, origin}

\author{
Chekulaev V.P., Arestova N.A., Egorova Yu.S. \\ IPGG RAS, St.Petersburg,vpchekulaev@mail.ru
}

\begin{abstract}
The data on the formation time and chemical composition of the Archean TTG rocks of the Karelian province (Fennoscandian shield) are summarized. The main stages of the formation of TT rocks in the age range from 3240 to 2650 Ma have been determined, i.e. from the Paleoarchean almost to the border of the Archean and Paleoproterozoic. The characteristic features of the composition of the rocks of all the stages identified are presented. Based on geological and isotopic data, it is shown that there is no petrogenetic relationship between the TT of rocks and metabasites of greenstone belts, as well as the absence of their possible relationship with subduction processes.

Key words: Archean, TTG, Karelian province, Fennoscandian shield.
\end{abstract}

\section{Введение}

Данная работа является попыткой обобщить в краткой форме имеющиеся на сегодняшний день данные по архейским ТТГ породам Карельской провинции Фенноскандинавского щита.

Восточная архейская часть Фенноскандинавского щита представлена тремя крупными фрагментами архейской коры или провинциями (Ранний докембрий ..., 2005): Кольско-Норвежской, Беломорской и Карельской. Геохронологические и изотопно-геохимические исследования последних десятилетий показали, что наиболее полно архейские ТТГ породы представлены в Карельской провинции, где они формировались в возрастном диапазоне от 3240 до 2650 млн. лет (Вревский и др., 2010; Чекулаев и др., 2018; Арестова и др., 2015), т.е. от палеоархея почти до границы архея и палеопротерозоя. Соответственно Карельская провинция является наиболее информативной для изучения этих пород в ходе их эволюции на протяжении почти 600 млн лет. Другой особенностью провинции является наличие в ее строении трех фрагментов (доменов или субпровинций), выделенных на основании различий в строении коры и во времени образования слагающих ее комплексов пород: Водлозерского, Западно-Карельского и Центрально-Карельского (Лобач-Жученко и др., 2000).

\section{Этапы ТТГ-магматизма в Карельской провинции}

В формировании коры Карельской провинции выделяются несколько этапов образования ТТГ пород. Наиболее широко ТТГ породы представлены в Водлозерском домене. Самые ранние ТТГ породы с возрастом около 3240 млн. лет присутствуют в центральной части Водлозерского домена (районы р. Водлы, р. Выг, Лайручья, рек Черева и Винела), но описаны также в северо-западной (финляндской) части провинции в районе Пудасъярви, где они образуют незначительный выход. 
Они характеризуются низкими содержаниями $\mathrm{K}, \mathrm{Rb}, \mathrm{Y}$, Th, отношениями $\mathrm{Rb} / \mathrm{Sr}$, более высокими содержаниями $\mathrm{Sr}$, отношениями $\mathrm{Sr} / \mathrm{Y},(\mathrm{La} / \mathrm{Yb})_{\mathrm{n}},(\mathrm{Gd} / \mathrm{Yb})_{\mathrm{n}},(\mathrm{La} / \mathrm{Sm})_{\mathrm{n}} \mathrm{Zr} / \mathrm{Y}$, в целом отличаясь от ТТГ пород последующих этапов. Такие особенности состава, в частности высокое отношение $(\mathrm{Gd} / \mathrm{Yb})_{\mathrm{n}}$, указывают на относительно глубинные условия формирования расплавов с образованием граната в рестите и переходом плагиоклаза в расплав. Это согласуется с высоким содержанием в них $\mathrm{Sr}$ и положительной аномалией $\mathrm{Eu}\left(\mathrm{Eu} / \mathrm{Eu}^{*}=1.22\right)$.

Следующий этап ТТГ-плутонизма, имевший место около 3150 млн. лет назад, представлен в краевых частях Водлозерского домена вблизи обрамляющих древних зеленокаменных поясов. Такие породы описаны также в Северной и в Центральной Финляндии. Тоналиты этого этапа отличаются от более ранних повышенными содержаниями $\mathrm{K}_{2} \mathrm{O}, \mathrm{Rb}, \mathrm{Y}$, REE и отсюда их суммой и более низкими отношениями $\mathrm{Sr} / \mathrm{Y}$ и $(\mathrm{La} / \mathrm{Yb})_{n}$ (рис. 1), что может отражать как иной состав источника, так и менее глубинные условия образования расплавов (Арестова и др., 2015; Чекулаев и др., 2018; Чекулаев, Глебовицкий, 2017).
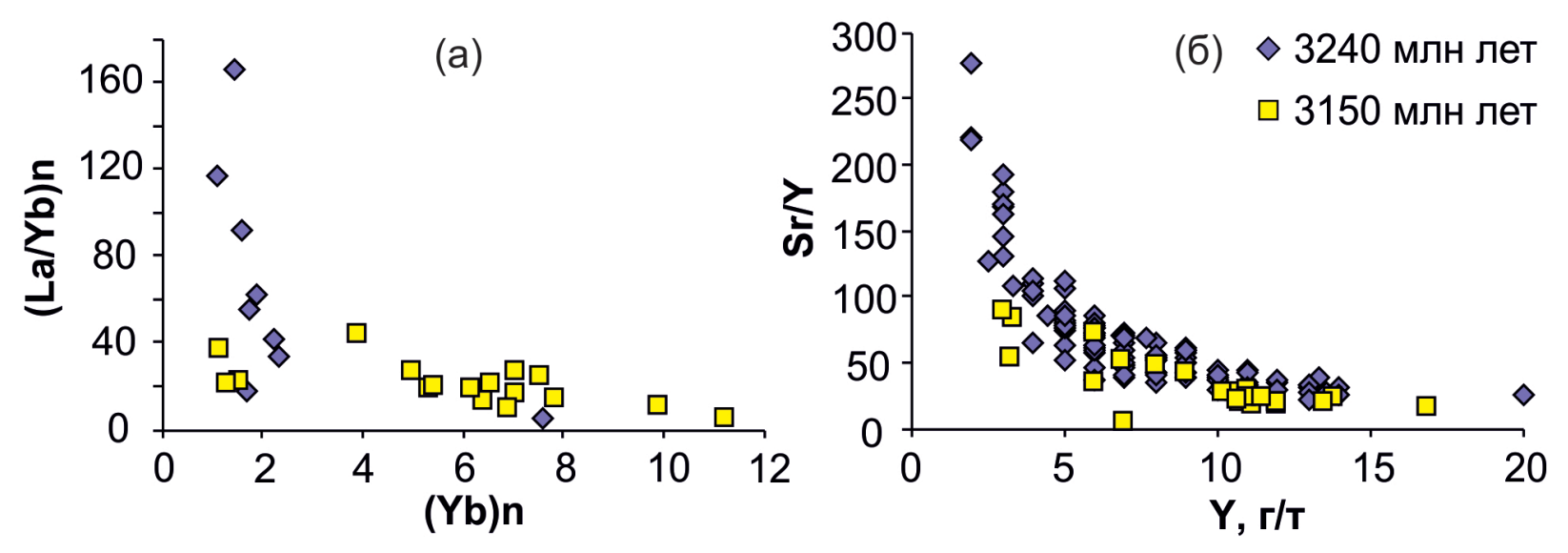

Рис. 1. Диаграммы: (a) - (La/Yb) $-(\mathrm{Yb})_{\mathrm{n}}$ и (б) $-\mathrm{Sr} / \mathrm{Y}-\mathrm{Y}$ для тоналитов Карельской провинции с возрастом $\sim 3240$ и 3150 млн. лет.

Fig. 1. Diagrams: $(\mathrm{a})-(\mathrm{La} / \mathrm{Yb})_{\mathrm{n}}$ vs $(\mathrm{Yb})_{\mathrm{n}}$ and $(\mathrm{b})-\mathrm{Sr} / \mathrm{Y}$ vs $\mathrm{Y}$ for tonalites of the Karelian province with ages of $\sim$ 3240 and $\sim 3150$ Ma.

Трондьемиты с возрастом около 2900 млн. лет представлены в западной краевой части Водлозерского домена на границах Семченской и Палаламбинской зеленокаменных структур. В районе Палой Ламбы трондьемиты образуют лейкосому мигматитов по тоналитам с возрастом $3141 \pm 10$ млн. лет, а на границе Семченской зеленокаменной структуры они слагают значительные площади, отделяя ТТГ породы фундамента от метавулканитов. Состав этих трондьемитов близок к составу тоналитов основания с возрастом около 3150 млн. лет, отличаясь большим содержанием в них $\mathrm{Sr}$ и меньшими содержаниями Y и $\mathrm{Zr}$, соответственно высоким отношением $\mathrm{Sr} / \mathrm{Y}$. Такой состав в сочетании с геологическими наблюдениями предполагает их образование в результате плавления тоналитов (Чекулаев, 1988; Арестова и др., 2015), что подтверждается, присутствием в них древнего ксеногенного циркона (Арестова и др., 2017), а также изотопным составом $\mathrm{Nd}$, согласно которому источник трондьемитов имеет возраст 3130-3150 млн. лет.

ТТГ магматизм в Водлозерском домене завершается внедрением интрузий тоналитов около 2850 млн. лет назад, которые не имеют широкого распространения и представлены на севере Шилосским массивом и на восточном берегу Онежского озера массивом в районе пос. Шальский. По содержанию $\mathrm{Sr}$, отношениям $(\mathrm{La} / \mathrm{Yb})_{\mathrm{n}}, \mathrm{Eu} / \mathrm{Eu}$ *, $\mathrm{Zr} / \mathrm{Y}$ эти тоналиты приближаются к ТТГ породам с возрастом 3150 млн. лет, но изотопный состав $\mathrm{Nd}$ указывает на их более молодой (меньше 3 млрд. лет) источник.

Породы ТТГ ассоциации Западно-Карельского домена с возрастом около 2.8 млрд. лет и модельным возрастом $\mathrm{t}_{\mathrm{DM}(\mathrm{Nd})}$ 2.9-3.0 млрд. лет, изученные в обрамлении зеленокаменных поясов Финляндии и в Западной Карелии (Чекулаев и др., 2018), имеют определенное сходство составов с ТТГ 
с возрастом около 2850 млн. лет. Главным отличием являются меньшая магнезиальность и обогащение западнокарельских пород высокозарядными (HFS) элементами, такими как $\mathrm{Y}, \mathrm{Nb}, \mathrm{Zr}, \mathrm{Pb}$, a также РЗЭ. Важно отметить, что такие отличия видны лишь при сравнении средних составов (Чекулаев, Глебовицкий, 2017), но не всегда видны на диаграммах, построенных на основе нормированных значений.

Наиболее поздние неоархейские ТТГ-породы, имеющие возраст около 2750 млн. лет и развитые почти исключительно в пределах Центрально-Карельского домена, заметно отличаются от пород предыдущих этапов по составу. По сравнению с мезоархейскими ТТГ Западно-Карельского и особенно Водлозерского домена они характеризуются более высокими содержаниями литофильных элементов $\mathrm{K}, \mathrm{Rb}, \mathrm{Sr}, \mathrm{Ba}, \mathrm{LREE}$, а также $\mathrm{Zr}$, и соответственно отношениями $\mathrm{Zr} / \mathrm{Y}, \mathrm{Sr} / \mathrm{Y}, \mathrm{La} / \mathrm{Yb}$, более низкой магнезиальностью mg\# (рис. 2), что свидетельствует (Чекулаев и др., 2018) об ином составе источника ТТГ расплавов.
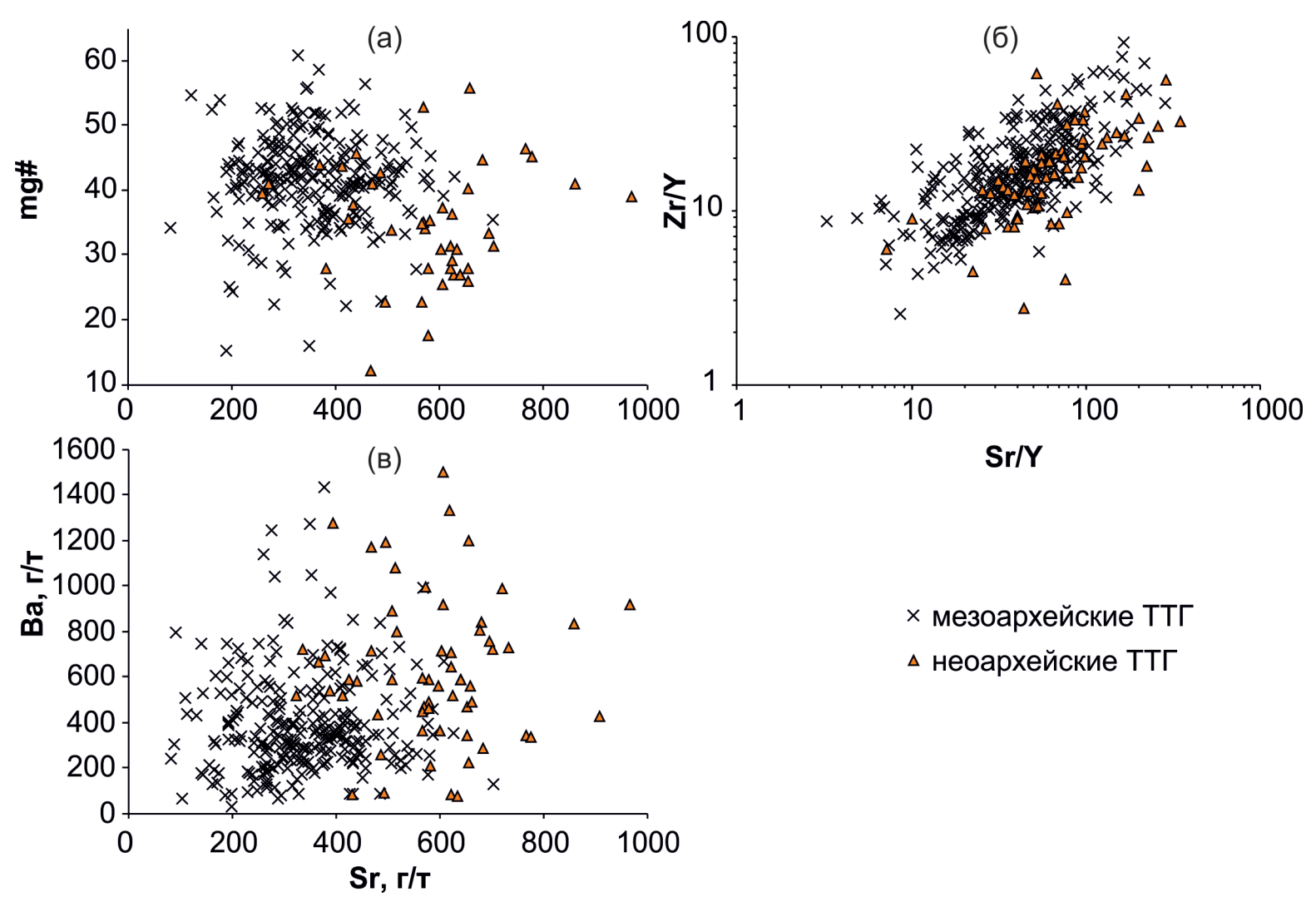

× мезоархейские ТТГ

$\Delta$ неоархейские ТТГ

Рис. 2. Диаграммы: (а) $\mathrm{Sr}-\mathrm{mg \# ,} \mathrm{(б)} \mathrm{Zr} / \mathrm{Y}-\mathrm{Sr} / \mathrm{Y}$, (в) $\mathrm{Sr}-\mathrm{Ba}$ для пород ТТГ ассоциации мезоархейского и неоархейского возраста Карельской провинции.

Fig. 2. Diagrams: (a) Sr vs mg \#, (б) Zr / Y vs Sr / Y, (в) Sr vs Ba for the Mesoarchean and Neoarchean TTG of the Karelian province.

\section{Условия формирования ТТГ пород Карельской провинции в архее}

Анализ распределения модельных возрастов $\mathrm{t}_{\mathrm{Nd( \textrm {DM } )}}$ и значений возраста пород по циркону показывает (рис. 3), что преобладающая часть мезоархейских ТТГ образовалась из протолитов, отделившихся от мантии задолго до выплавления из них ТТГ расплавов (Вревский и др., 2010). Эти особенности изотопной эволюции $\varepsilon_{\mathrm{Nd}}(\mathrm{t})$ исключают предположение о формировании большей части TTГ из толеитов зеленокаменных поясов, а значения $\mathrm{t}_{\mathrm{DM}}(\mathrm{Nd})$, значительно превышающие возраст становления ТТГ, исключают их генетическую связь с субдукцией древней океанической коры. Анализ изотопии $\mathrm{Sm}$ и $\mathrm{Nd}$ указывает также на отсутствие петрогенетической связи между вулканитами зеленокаменных поясов и ТТГ-породами. Проведенный расчет допустимого значения от- 


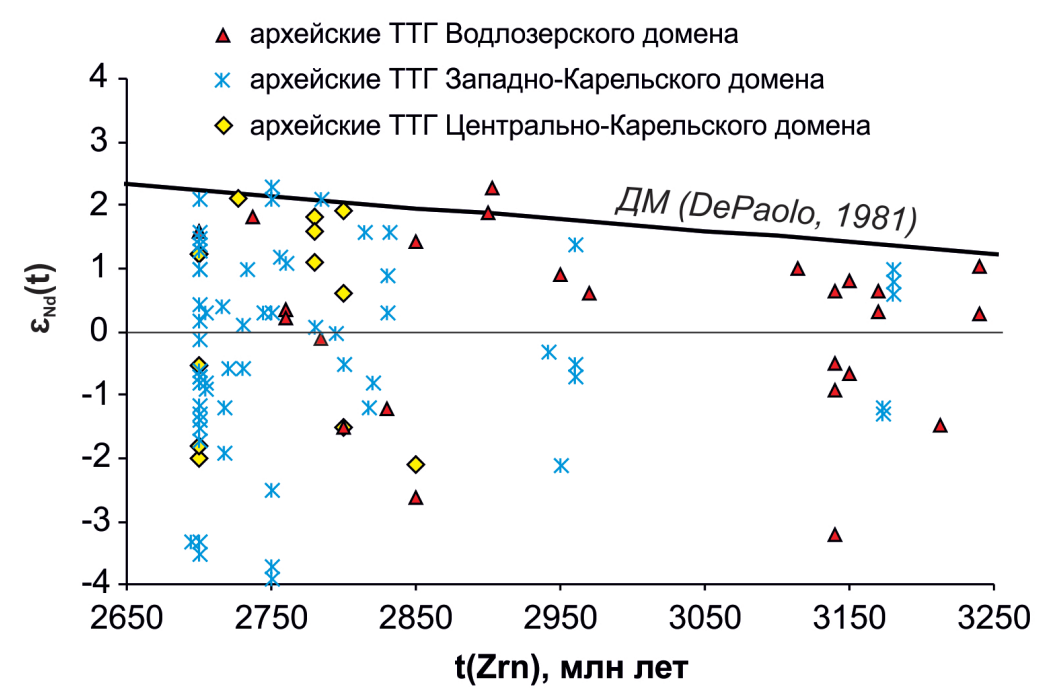

Рис. 3. Диаграмма «возраст $-\varepsilon_{\mathrm{Nd}}(\mathrm{t}) »$ для архейских ТТГ Карельской провинции.

Fig. 3. Age vs $\varepsilon_{\mathrm{Nd}}(\mathrm{t})$ diagram Archean Karelian TTG.

ношения $\mathrm{Sm} / \mathrm{Nd}$ для базитового источника ТТГ показал (Лобач-Жученко и др., 1999; Вревский и др., 2010), что оно не должно было превышать значения 0.27-0.30. Такими геохимическими характеристиками обладают мафиты, обогащенные Nd (ENd-мафиты) (Ветрин, 2006; Kempton et al., 1995 и др.), тогда как в базальтах эти отношения превышают 0.30. Соответственно, их источнику больше соответствуют базиты нижней коры или ранние амфиболиты Водлозерского домена с возрастом около 3.24 млрд. лет, что подтверждается результатами петрологического моделирования по главным и редким элементам, проведенного для тоналитов района р. Выг (Лобач-Жученко и др., 1999; Вревский и др., 2010).

Более молодые неоархейские ТТ-породы Центрально-Карельского домена обогащены литофильными элементами, в первую очередь $\mathrm{Sr}$. При этом изотопные данные указывают на незначительный интервал времени между формированием ТТГ и базитов зеленокаменных поясов, а геологические данные - на более молодой возраст метавулканитов, которые не могли быть источником ТТ расплавов.

\section{Модели образования ТТГ расплавов}

Возможные модели образования ТТГ расплавов рассматривались многими исследователями. В основном обсуждаются два принципиально различных типа моделей образования ТТГ пород древних кратонов: (1) субдукционная - плавление метаморфизованных базальтов океанических литосферных плит, фрагменты которых представлены толеитами зеленокаменных поясов, и (2) плюмтектоническая - плавление нижней части мощной мафитовой коры. На основании некоторых особенностей состава (повышенные $\mathrm{MgO}, \mathrm{Cr}, \mathrm{Ni}$ в сочетании с высокими содержаниями литофильных элементов) ТТГ и адакитов по сравнению с экспериментальными расплавами многие исследователи (Moyen, Martin, 2012 и др.) объясняют взаимодействием ТT-расплавов с мантийным клином в субдукционной обстановке. Однако более высокую магнезиальность ТТ пород может обеспечить более низкая температура плавления источника, когда кристаллизуется более железистый гранат, либо подчиненное количество клинопироксена или роговой обманки в рестите (Вревский и др., 2010; Чекулаев, в печати). Подобное влияние состава реститовых фаз уже отмечалось (Туркина, 2000 и др.). Одновременно было показано (Condie, 2005; Smithies, 2000 и др.), что ТТГ не являются аналогами адакитов, обнаруживая существенные геохимические отличия, главными из которых являются высокие (>0.60) значения mg\# и содержания $\mathrm{Sr}$ более 1000 г/т (Чекулаев и др., 2018) в адакитах.

Против субдукционной модели образования ТТГ Карелии свидетельствует также сравнение их состава с плагиогранитоидами современных геодинамических обстановок, которое показало (Че- 
кулаев, 2009; Вревский и др., 2010), что архейские ТТГ заметно отличаются от фанерозойских плагиогранитоидов не только формой и размерами массивов, но и рядом геохимических особенностей. Так, фанерозойские плагиогранитоиды содержат заметно больше HREE, Sc, Y и Ti (Condie, 1986; Чекулаев, 2009). Кроме того, мезоархейские ТТГ Карелии близки по составу вулканитам, которые также демонстрируют заметное отличие от вулканитов современных геодинамических обстановок.

Таким образом, перечисленные выше особенности геологического строения, изотопного и геохимического состава архейских ТТГ серий Карельской провинции в совокупности с петрологическими и экспериментальными данными, модельными расчетами наиболее полно могут быть объяснены в рамках модели их образования в результате плавления мафитов нижней коры под воздействием плюма. При этом неоархейские плутонические и магматические породы заметно отличаются по составу от мезоархейских, вероятно, отражая смену геодинамической обстановки.

Работа выполнена в рамках темы НИР № FMNU-2019-0001.

\section{Литература}

1. Арестова Н.А., Чекулаев В.П., Лобач-Жученко С.Б., Кучеровский Г.А. Корреляция процессов формирования архейской коры древнего Водлозерского домена (Балтийский щит) // Стратиграфия. Геол. корреляция. 2015. Т. 23. № 2. С. 1-13.

2. Арестова Н.А, Чекулаев В.П., Кучеровский Г.А. и др. О соответствии геологических данных и результатов датирования архейских пород U-Pb методом по циркону на примере Карельской провинции Балтийского щита // Региональная геология и металлогения. 2017. № 71. С. 35-52.

3. Ветрин В.Р. Состав и строение нижней коры Беломорского подвижного пояса, Балтийский щит // Петрология. 2006. Т. 14. № 4. С. 415-438.

4. Вревский А.Б., Лобач-Жученко С.Б., Чекулаев В.П. и др. Геологические, петрологические и изотопно- геохимические ограничения геодинамических моделей образования тоналит-трондьемитгранодиоритовых ассоциаций древних кратонов // Геотектоника. 2010. № 4. С. 20-38.

5. Лобач-Жученко С.Б, Арестова Н.А., Чекулаев В.П. и др. Эволюция Южно-Выгозерского зеленокаменного пояса Карелии // Петрология. 1999. Т. 7. № 2. С. 156-173.

6. Лобач-Жученко С.Б., Чекулаев В.П., Арестова Н.А. и др. Архейские террейны Карелии: их геологическое и изотопно-геохимическое обоснование // Геотектоника. 2000. № 6. С. 26-42.

7. Ранний докембрий Балтийского щита (ред. В.А. Глебовицкий). СПб. Изд-во: Наука. 2005. 711 с.

8. Туркина О.М. Модельные геохимические типы тоналит-трондьемитовых расплавов и их природные эквиваленты // Геохимия. 2000. № 7. С. 704-717.

9. Чекулаев В.П. Особенности структурно-метаморфической эволюции зеленокаменных поясов. Деформации и метаморфизм лопийских образований Западной Карелии // Зеленокаменные пояса фундамента Восточно-Европейской платформы (геология и петрология вулканитов). Изд-во:Наука. 1988. С. 62-68.

10. Чекулаев В.П. Геология и состав архейских TTG и плагиогранитов фанерозойских геодинамических обстановок: сходство и отличие // Гранит-зеленокаменные системы архея и их поздние аналоги. Материалы научной конференции. 2009. Петрозаводск. С. 176-179.

11. Чекулаев В.П., Арестова Н.А., Егорова Ю.С., Кучеровский Г.А. Изменение условий формирования коры Карельской провинции Балтийского щита прт переходе от мезо- к неоархею: результаты геохимических исследований // Стратиграфия. Геол. корреляция. 2018. Т. 26. № 3. С. 3-23.

12. Чекулаев В.П., Глебовицкий В.А. О среднем составе ТТГ (тоналит-трондьемит-гранодиоритовой) ассоциации: возможности использования // Докл. АН. 2017. Т. 472. № 2. С. 192-196.

13. Condie K.C. Origin and early growth rate of continents // Precambrian. Res. 1986. V. 32. № 4. P. 261-278.

14. Condie K.C. High field strength element ratios in Archean basalts: a window to evolving sources of mantle plumes? // Lithos. 2005. V. 79. P. 491-504.

15. DePaolo D.J. Neodymium isotopes in the Colorado Front Range and crust mantle evolution in the Proterozoic // Nature. 1981. V. 291. P. 193-196.

16. Kempton P.D, Downes H, Sharkov E.V. et al. Petrology and geochemistry of xenoliths from the Northern Baltic Shield: evidence for partial melting and metasomatism in the lower crust beneath an Archaean terrane // Lithos. 1995. V. 36. P. 157-184

17. Moyen J.-F., Martin H. Forty years of TTG research // Lithos. 2012. V. 148. P. 312-336.

18. Martin H. The adakitic magmas: modern analogues of Archaean granitoids // Lithos. 1999. V. 46. P. 411-429.

19. Smithies R.H. The Archaean tonalite-trondhjemite-granodiorite (TTG) series is not an analogue of Cenozoic adakite // Earth Planet. Sci. Lett. 2000. V. 182. P. 115-125. 